\title{
An Overview of Control Method with Various Crowbar Techniques of Wind Turbines during Power System Faults
}

\author{
I. Hamdan ${ }^{1 \square}$, Omar Noureldeen ${ }^{2}$ \\ ( ${ }^{1}$ https://orcid.org/0000-0002-9860-4739)
}

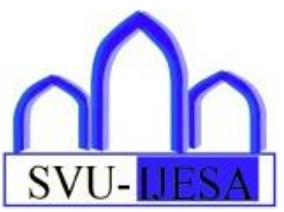

\begin{abstract}
This paper reviews the various control crowbar methods associated with doubly-fed induction generator (DFIG) wind energy system (WES) during power system faults. The crowbar control methods are designed to improve the fault ride-through (FRT) capability of DFIGs based on WESs. The adaptive neural-fuzzy inference system (ANFIS) is developed to detect the fault conditions and control the crowbar protection techniques. The proposed ANFIS crowbar protection technique detects the fault based on the measurement of the three phase voltages and currents at the terminals of the DFIG wind turbine (WT) to activate the crowbar protection system during fault period and deactivate it after fault clearance. Furthermore, the proposed ANFIS crowbar techniques are investigated to enhance the stability of studied WT generators and also, it designed to protect system components. All these simulations are carried for the model consists of 9 MW DFIG WTs connected to the grid model in Simulink/Matlab. Simulation results also revealed that outer terminal crowbar is more effective as compare with other crowbar techniques via ANFIS control strategy.
\end{abstract}

Keywords: ANFIS; Control Strategy; Crowbar; DFIG Wind Turbine; Power Electronic Converters; Faults.

\section{Introduction}

Wind energy technology has grown significantly in the

Received: 13 June 2021/ Accepted: 30 June 2021

$\square$ Corresponding Author

${ }^{1}$ I. Hamdan, E-mail: IbrahimHamdan86@eng.svu.edu.eg

${ }^{2}$ Omar Noureldeen, E-mail: omar_noureldeen@ @ svu.edu.eg

${ }_{1,2}$ Department of Electrical Engineering, Faculty of Engineering, South Valley University, Qena, 83523, Egypt last few decades. Wind farm based DFIG system has gained considerable academic attention and industrial applications in the recent years. In practical applications, the DFIG is gradually maturing as technology for a type of variable speed WT utilization. DFIG is the most competitive option in terms of balance between the technical performance and economic costs $[1,2]$. Many researchers have been focused their attentions on protection techniques for WTs in the recent years. The DFIG contains converters and DC-link capacitor where these components are sensitive to faults. During the faults occurrence, the short circuit current flowing through DFIG windings, power converters and DC-link capacitor may be high current then can cause any risk of damage of these components. It is increasingly important that turbine generators stay connected and support the grid transmission network during faults so-called low voltage ride-through (LVRT) or fault ride-through (FRT), which is specified by various grid codes.

The LVRT capability enhancement of WT generator system during network disturbance is designed in [3]. The justified FRT requirements for WTs in power systems are introduced in [4]. An active crowbar for DFIG-based WT during gird faults is presented in [5]. The technologies of FRT for DFIG-WTs are mentioned in [6]. A SCR crowbar is studied with converter for WTs in [7]. Also, minimum-threshold crowbar for a DFIG-WT is analysed in [8]. A review of published the crowbar protection techniques are discussed in [9-13]. [14-16] mentioned that both DC-brake chopper and crowbar are necessary for FRT capability to protect the DFIG components from over-current and over-voltage. However, the different protection techniques are turned on/off via control strategy called ANFIS. The ANFIS networks depend on the number of fuzzy membership functions and the number of 
neurons that used for rule base to consist of the main construction of these networks [17-23]. The ANFIS structures have well known advantages of control and modelling for a highly non-linear system, as it combines the capability of FLC and ANN [24-27]. Thus, the ANFIS is developed to use as a protection technique, which also automatically control the protection techniques and monitoring as fault detection for the WTs system. The objective of this paper is to compare the different crowbar protection techniques by using ANFIS for studied system. The simulation study is carried out for different crowbar strategies to improve the fault ride-through capability of DFIGs based on wind energy conversion systems. A detailed comparison of simulation results is also provided, where all techniques are designed based on proposed ANFIS approach to validate the robustness of proposed techniques during fault occurrence. The paper is distributed as follows: Section 2describes the general structure of WES. Section 3 presents the different crowbar protection techniques. Section 4 discusses the proposed control strategy. Section 5 achieves the detailed and comparative study of simulation results for different tasks. Lastly, Section 6 draws the conclusion.

\section{Wind Energy Description and Configuration}

The general structure of grid integrated WES is illustrated in Fig. 1. The WES consists of various main parts such as WT rotor, gearbox, generator, power converters, and transformer for grid connection.

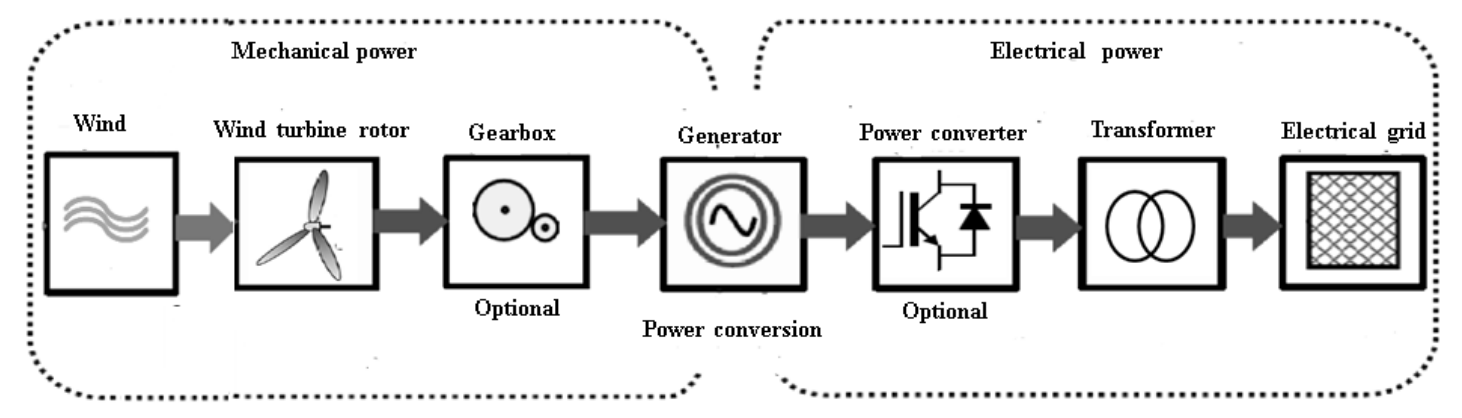

Fig. 1 Diagram representation of WES.

The DFIG is most popular wind generator in the market efficiency [17-21]. The main representation of grid among variable-speed WTs, because of their high energy integration with DFIG-WT is shown as Fig. 2.

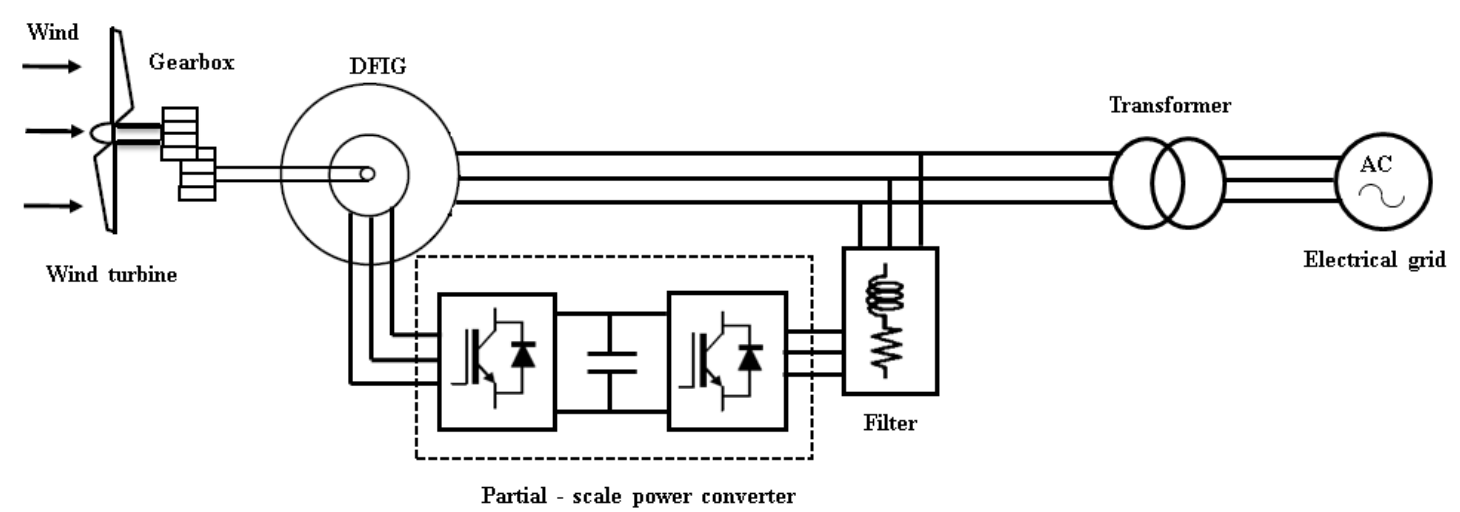

Fig. 2 Variable speed DFIG-WT with partial-scale power converter.

The DFIG model in the direct (d) and quadrature (q) reference frame is analyzed as follows [19]:

$$
\left[\begin{array}{l}
V_{d s} \\
V_{q s}
\end{array}\right]=\left[\begin{array}{cc}
R_{S} & 0 \\
0 & R_{S}
\end{array}\right]\left[\begin{array}{l}
I_{d s} \\
I_{q s}
\end{array}\right]+\frac{d}{d t}\left[\begin{array}{l}
\lambda_{d s} \\
\lambda_{q s}
\end{array}\right]+\left[\begin{array}{cc}
0 & -\omega_{e} \\
\omega_{e} & 0
\end{array}\right]\left[\begin{array}{l}
\lambda_{d s} \\
\lambda_{q s}
\end{array}\right](1)
$$


$\left[\begin{array}{l}V_{d r} \\ V_{q r}\end{array}\right]=\left[\begin{array}{cc}R_{r} & 0 \\ 0 & R_{r}\end{array}\right]\left[\begin{array}{l}I_{d r} \\ I_{q r}\end{array}\right]+\frac{d}{d t}\left[\begin{array}{l}\lambda_{d r} \\ \lambda_{q r}\end{array}\right]+\left[\begin{array}{cc}0 & -\left(\omega_{e}-\omega_{r}\right) \\ \omega_{e}-\omega_{r} & 0\end{array}\right]\left[\begin{array}{l}\lambda_{d r} \\ \lambda_{q r}\end{array}\right]$

$\left[\begin{array}{l}\lambda_{d s} \\ \lambda_{q s} \\ \lambda_{d r} \\ \lambda_{q s}\end{array}\right]=\left[\begin{array}{cccc}L_{s} & 0 & L_{m} & 0 \\ 0 & L_{s} & 0 & L_{m} \\ L_{m} & 0 & L_{r} & 0 \\ 0 & L_{m} & 0 & L_{r}\end{array}\right]\left[\begin{array}{c}I_{d s} \\ I_{q s} \\ I_{d r} \\ I_{q s}\end{array}\right]$

where $V$ is the voltage, $I$ is the current, $R$ is the resistance, $\lambda$ is the flux linkage, $L$ is the inductance, $\omega_{e}$ is the supply angular speed, and $\varpi_{r}$ is the rotor angular speed. Also, the indices $s$ is the stator, $r$ is rotor, $m$ is the mutual, $d$ is the direct, and $q$ is the quadrature.

The active and reactive power at the stator and rotor windings can be expressed respectively as follows:

$$
\begin{aligned}
& P_{s}=V_{d s} I_{d s}+V_{q s} I_{q s} \\
& Q_{s}=V_{q s} I_{d s}-V_{d s} I_{q s} \\
& P_{r}=V_{d r} I_{d r}+V_{q r} I_{q r} \\
& Q_{r}=V_{q r} I_{d r}-V_{d r} I_{q r}
\end{aligned}
$$

Also, the total active and reactive power at stator and rotor windings can be expressed respectively as follows:

$$
P=P_{s}+P_{r}
$$

$$
Q=Q_{s}+Q_{r}
$$

\section{Various Crowbar Techniques}

Recently, the grid code requires that the WF must stay connected to grid for a specified duration time during fault conditions. Thus, extra protection techniques must be established to prevent the power system failure and also, to avoid the damage of DFIG power electronic components. The crowbar techniques are important to prevent the disconnection of DFIG-WTs during grid fault conditions. Many researches present various crowbar techniques [5-13]. The operation and construction of these crowbar techniques are discussed in the following subsections.

\subsection{DC crowbar technique}

The DC crowbar circuit is represented by a resistor in series with an IGBT switch, where it is connected to DFIG converters as shown in Fig. 3. The DC Crowbar protection technique is connected in parallel with the DC-link capacitor to protect it during faults. The excess active power during fault occurrence will be dissipated in the resistor of crowbar circuit. Also, the crowbar circuit is controlled to regulate the voltage of DCLC and limit the overcharge during fault occurrence. Also, the switching control signal for the crowbar circuit is automatically turned on/off whenever the DC-link voltage rises over/under its threshold value.

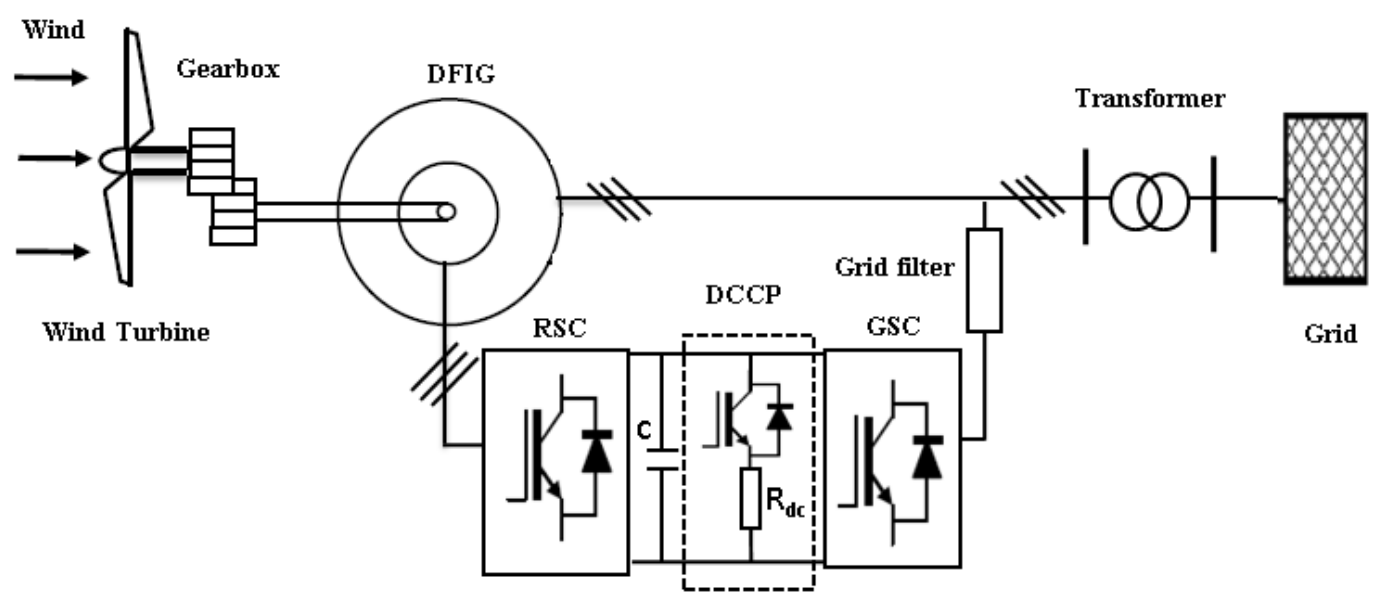

Fig. 3 Diagram representation of DFIG-WToperated with DCCP circuit.

\subsection{Traditional rotor crowbar technique}

Traditionally, the crowbar is connected in parallel with the rotor circuit and disabling the rotor converter then the
DFIG is converted to a singly fed induction generator. It consists of three resistances crowbar in series with bidirectional static switches as shown in Fig. 4. In the case of occurring faults, the crowbar resistors provide with a 
new path to the fault current through the crowbar resistance and protecting the converters, then after the clearing of the fault, the crowbar is removed and the rotor converter is reconnected again.

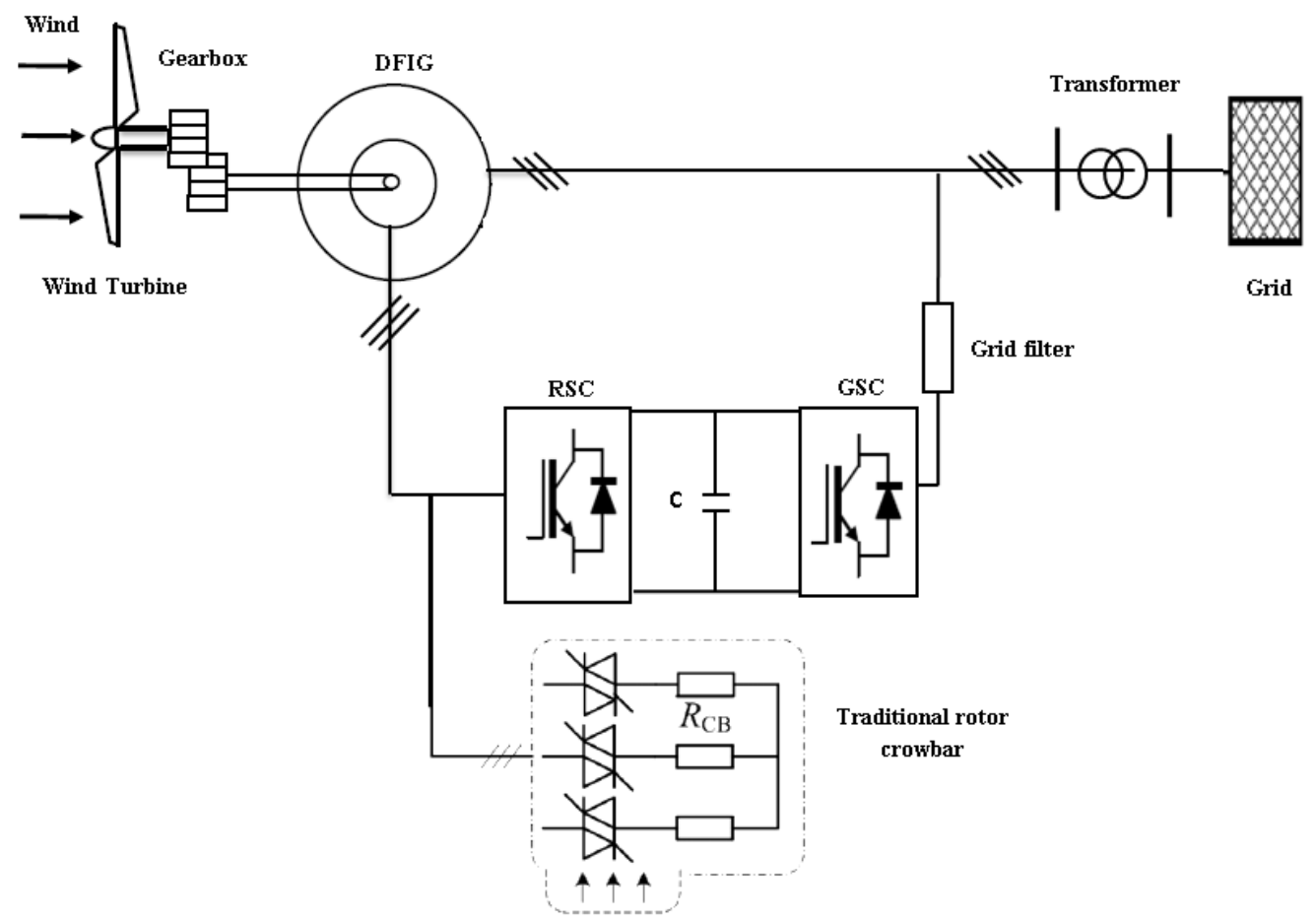

Fig. 4 Diagram representation of DFIG-WT operated with traditional rotor crowbar circuit.

\subsection{Stator series crowbar technique}

The crowbar is inserted internally between the stator windings and the grid as shown in Fig. 5, named as stator series crowbar protection technique. It consists of three resistances crowbar in parallel with bidirectional static switches. Their operations are different from the traditional crowbar. Under the ideal grid conditions, the currents flow through the bypass switches by turning the switches on, where the static switches remain closed and the stator current will not pass through stator crowbar resistances. Under fault conditions, the fault currents are forced to flow through the resistances by turning the switches off. Thus, these switches are triggered off only when a fault is detected, where, in this case, the stator current will pass through stator crowbar resistance and then the stator crowbar resistances will be in connected series with the stator windings.

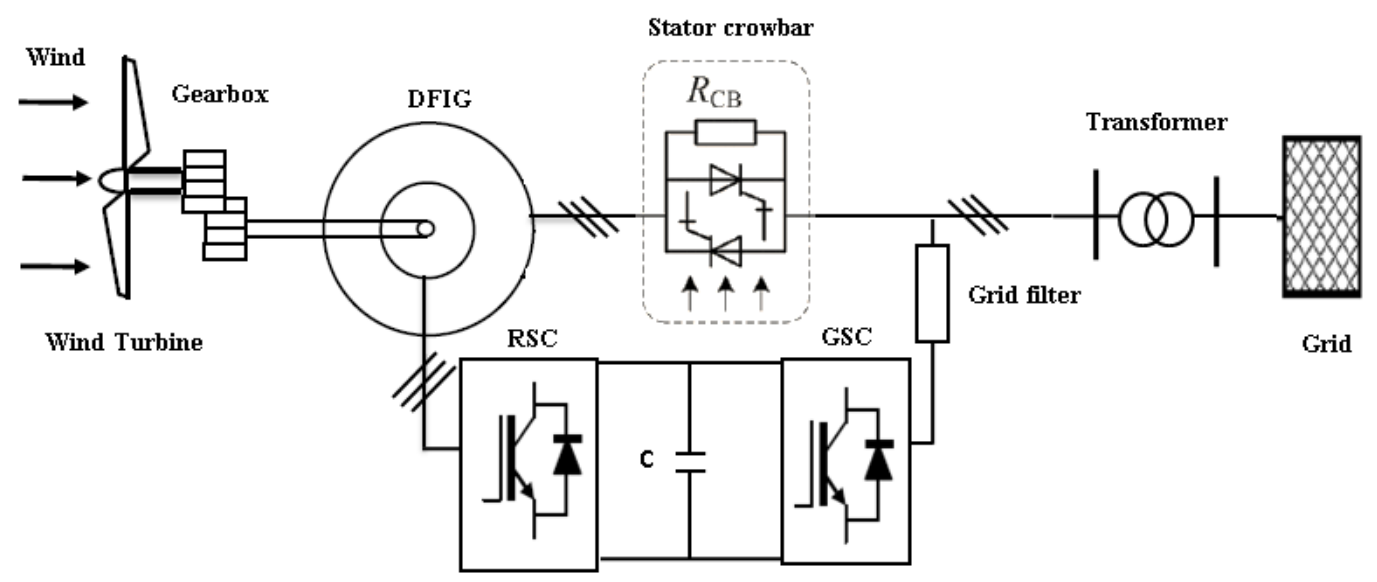

Fig. 5 Diagram representation of DFIG-WT operated with stator series crowbar circuit.

3.4 Outer terminal crowbar technique
The outer terminal crowbar protection technique consists of three resistors which are connected in parallel 
with bidirectional static switches. In normal conditions, the switches remain closed and the currents are passing through it. During fault occurrence, these switches are opened, and then the currents will be passing through crowbar resistors. In addition, the outer crowbar is similar to the stator series crowbar but the difference between two techniques is that the outer crowbar connected in series with the terminal of DFIG instead of the stator winding only, which is inserted between the terminals of DFIG-WT and the electrical grid, hence the derived name of 'outer' as shown in Fig. 6.

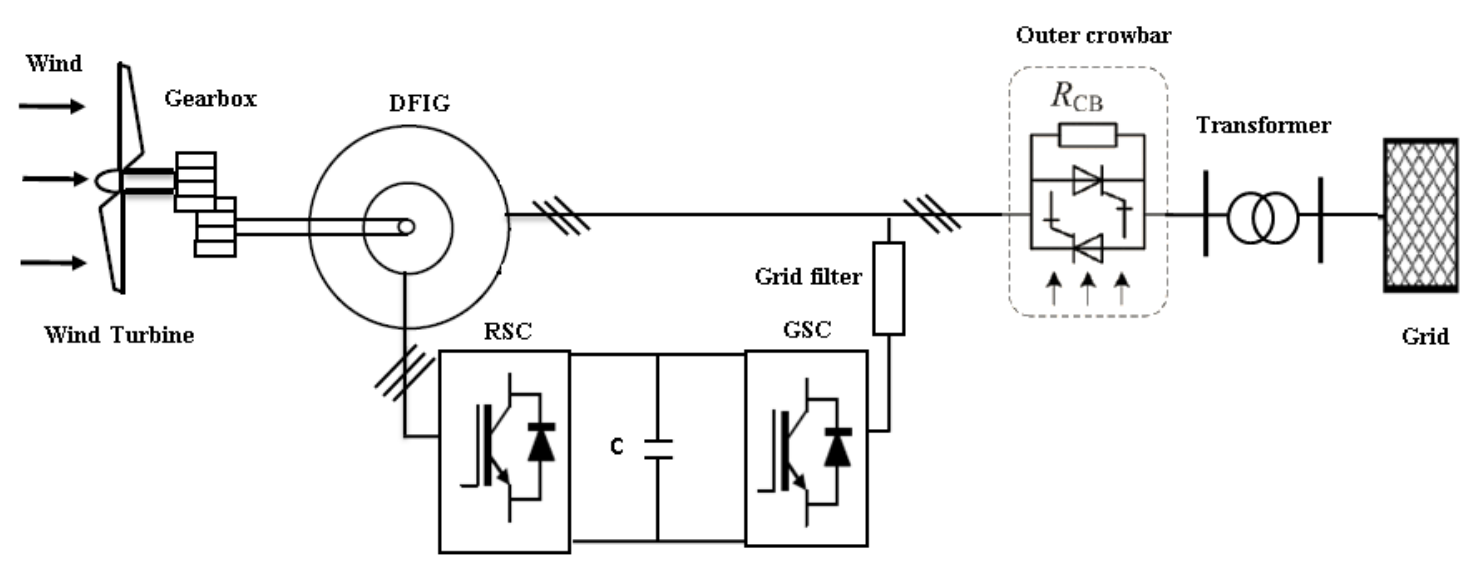

Fig. 6 Diagram representation of DFIG-WT operated with outer crowbar circuit.

\section{Control Strategy}

The conventional control strategy of the crowbar techniques can provide the switching strategies to trigger the switches of crowbar resistors depending on different standards by the comparator, such as the DC-link over-voltage or rotor over-current during the fault occurrence [6]. The proposed control strategy is based on the ANFIS network. ANFIS network is a data learning algorithm that uses the fuzzy logic system to transform the given inputs into a desired output via highly interconnected artificial neural network processing elements and information connections, which it is weighted to map the numerical inputs into output. The structure of ANFIS network is based on Takagi-Sugeno technique, thus fuzzy inference system is described by a set of fuzzy IF-THEN rules that have adapted via learning algorithm of neural network [17-27]. The inputs of ANFIS are the measured root mean square values of the three phase voltages and currents at DFIG-WT terminals, where these inputs are (Vabc, Iabc). The output of ANFIS is a control signal to activate or deactivate the crowbar technique. The structure of ANFIS algorithm with two inputs and one output are shown in Fig. 7. The parameters of ANFIS structure are chosen as follows, two inputs and three membership functions (MFs) for each input, the type of inputs MF is Gaussian, the outputs is constant, the error tolerance was chosen to be zero, the number of epochs is 300 , grid partitions, and the optimization method is hybrid algorithm. The ANFIS approach for the studied problem consists of two inputs as are phase currents and voltages which are fuzzified with membership functions and trained according to the training data to get the best membership functions parameters, then testing the ANFIS via training data to validate and check the algorithm. The desired outputs of ANFIS's are 1 or 0 for detection of faults. Moreover, the parameters of ANFIS approach are chosen to achieve the ANFIS network as a fault detector is ' 0 ' in case of un-faulted conditions and ' 1 ' in case of faulted conditions for the studied system.

For the sake of clarity of presentation, the proposed algorithm comprises of the following five basic steps:

Step 1. Acquire phase RMS voltages.

Step 2. Acquire phase RMS currents.

Step 3. Detect fault.

Step 4. Send the output control signal of ANFIS to the crowbar control technique.

Step 5. Turn on the crowbar technique during fault occurrence and turn off it after fault clearance.

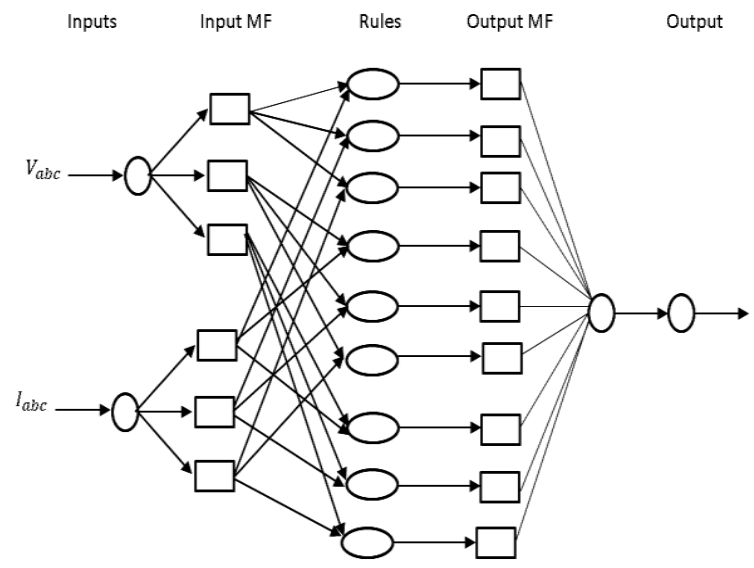

Fig. 7 ANFIS network architecture. 


\section{Results and Discussion}

A typical studied test system of $9 \mathrm{MW}$ wind power plant which composing of $6 \times 1.5 \mathrm{MW}$ WTs that connected to a $25 \mathrm{kV}$ distribution system and export the power through a $30 \mathrm{~km}$ transmission line to a $220 \mathrm{kV}$ electrical grid. The simulated wind speed of studied system is $10 \mathrm{~m} / \mathrm{s}$ and also, the value of DC voltage of DC-link capacitor is $1200 \mathrm{~V}$. The simulated short circuit occurrence is a three line to ground fault is applied at a point common coupling (PCC) as the terminal of studied WTs, where the fault period occurs for $150 \mathrm{~ms}$ from the instant of $1.5 \mathrm{~s}$ to the instant of $1.65 \mathrm{~s}$ from the simulation time.

\subsection{Different task study}

In this subsection, the test simulations under various tasks are performed. The control crowbar technique is necessary to avoid a disconnecting of DFIG-WTs during grid faults. The conventional control switching strategy of the different crowbar techniques are triggered when a short circuit occurred which leads to high increasing of the DC-link voltage and rotor current. Moreover, this paper presented artificial intelligence (AI) which uses as a control protection technique, where ANFIS is utilized as an AI technique and it can be used as an on-line fault detector. ANFIS controllable different crowbar protection techniques are presented to protect the DFIG WTs grid connected during power system faults.

The different studies of crowbar techniques via ANFIS control strategy are investigated. To study the performance of the wind system during faults, there are five simulation tasks performed as the following.

The first task studies the dynamic behavior of studied wind system in case of without any crowbar technique. The control system of the converter will be not lost during fault occurrence to study the behavior of the studied DFIG-WTs. The variations of DC-link voltage, active power, and reactive power are illustrated in Fig. 8 .
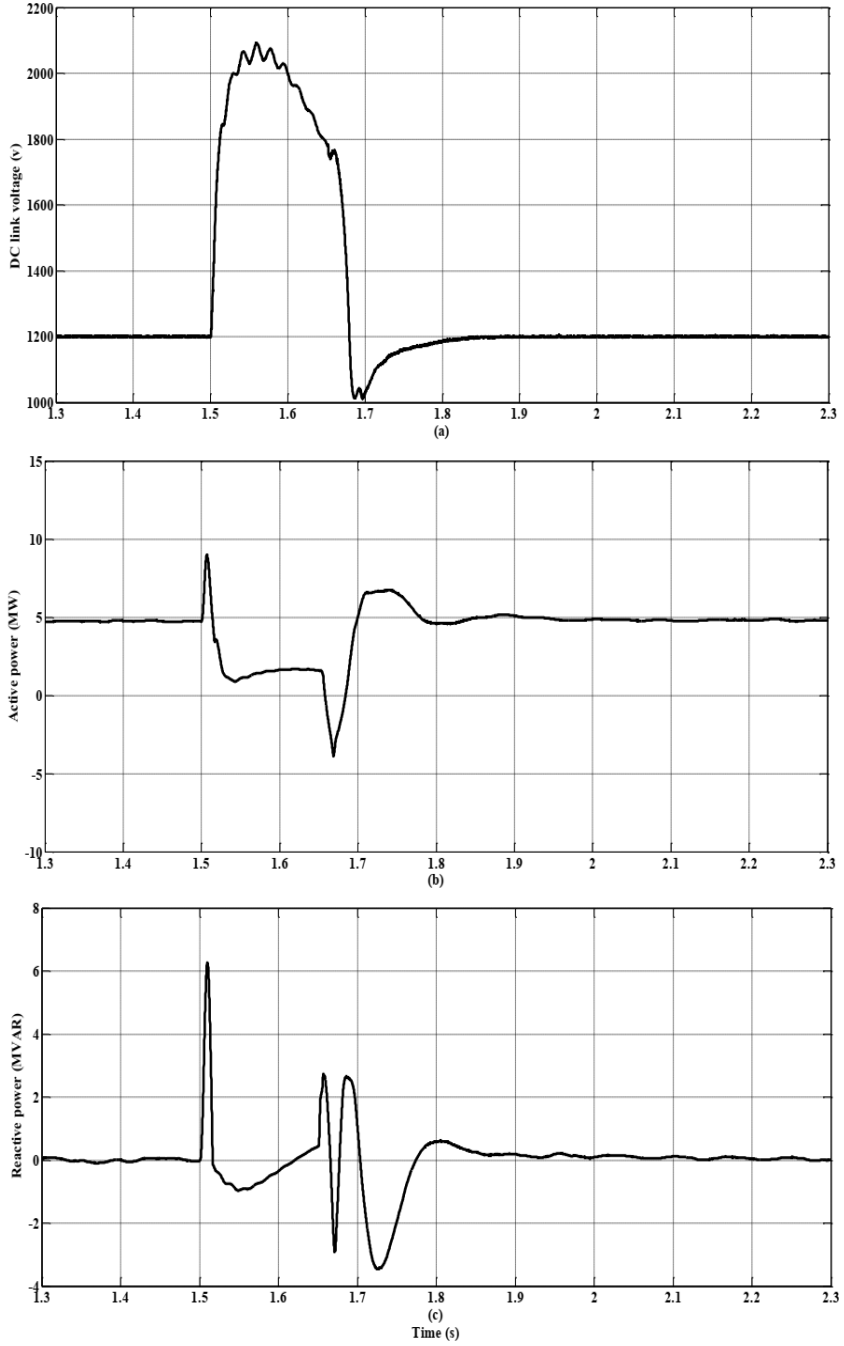

Fig. 8 Performance of studied system in case of without crowbar technique.

The second task studies the dynamic behavior of studied wind system with the DC crowbar technique. The switch is triggered via ANFIS strategy, and the control system of the converter will be not lost during fault occurrence. The variations of DC-link voltage, active power, and reactive power are illustrated in Fig. 9. 

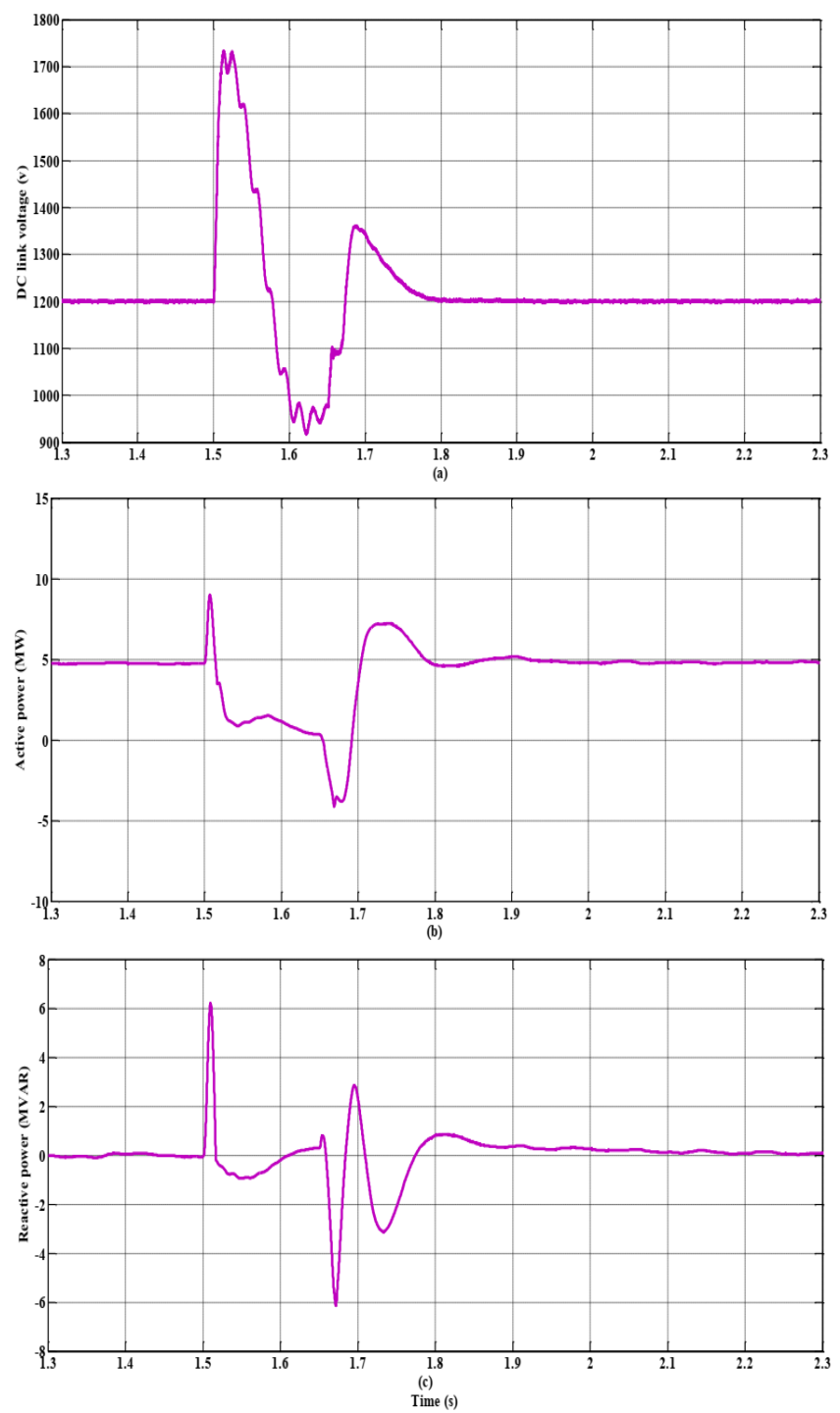

Fig. 9 Performance of studied system in case of DC crowbar technique.

The third task studies the dynamic behavior of studied wind system with the traditional rotor crowbar technique. The bidirectional static switches are triggered via ANFIS strategy, hence the rotor windings are connected by crowbar resistances and the rotor side converter is disconnected, so the control system of the converter will be lost during fault occurrence. The variations of DC-link voltage, active power, and reactive power are illustrated in Fig. 10.
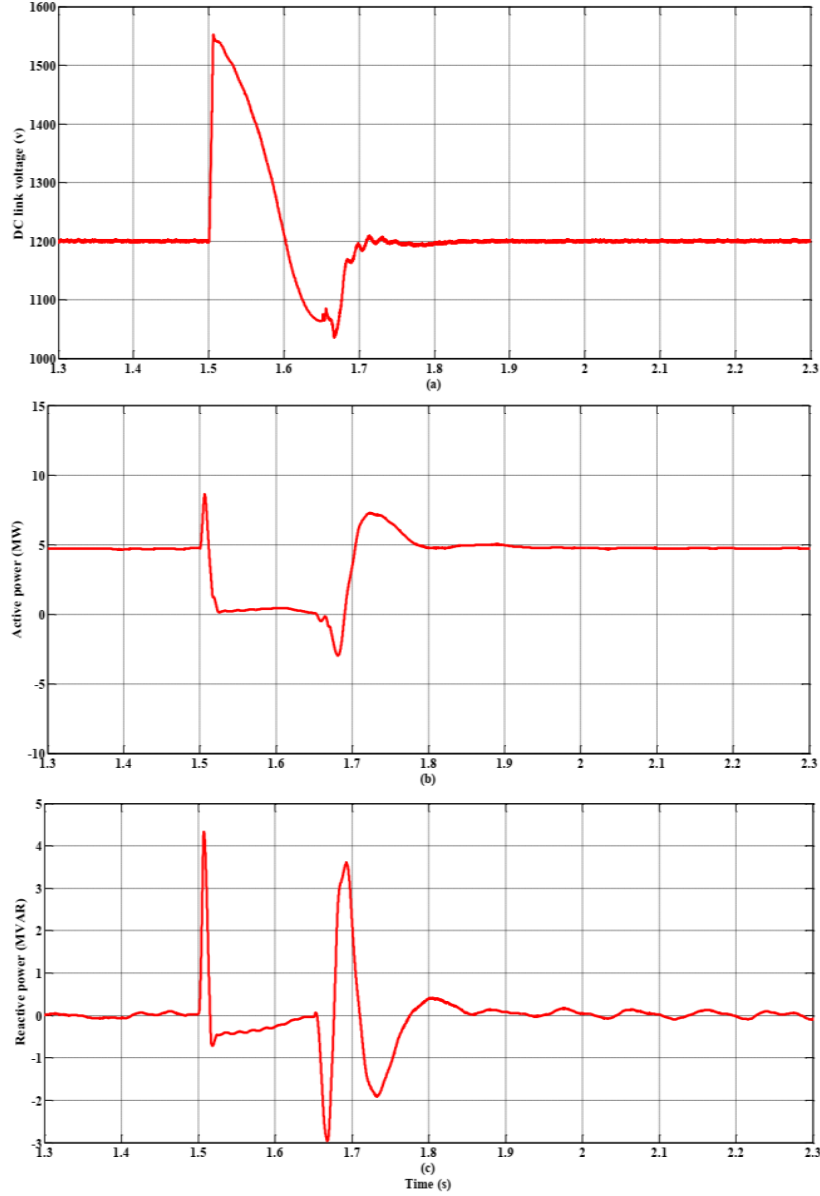

Fig. 10 Performance of studied system in case of traditional rotor crowbar technique.

The fourth task studies the dynamic behavior of studied wind system with the stator series crowbar technique. The bidirectional static switches are turned on during normal operation and these switches are turned off during the fault occurrence so the current will pass through the crowbar resistance. Also, the control system of the converter is still connected during fault occurrence, so the controllability of system will not be lost. The variations of DC-link voltage, active power, and reactive power are illustrated in Fig. 11. 

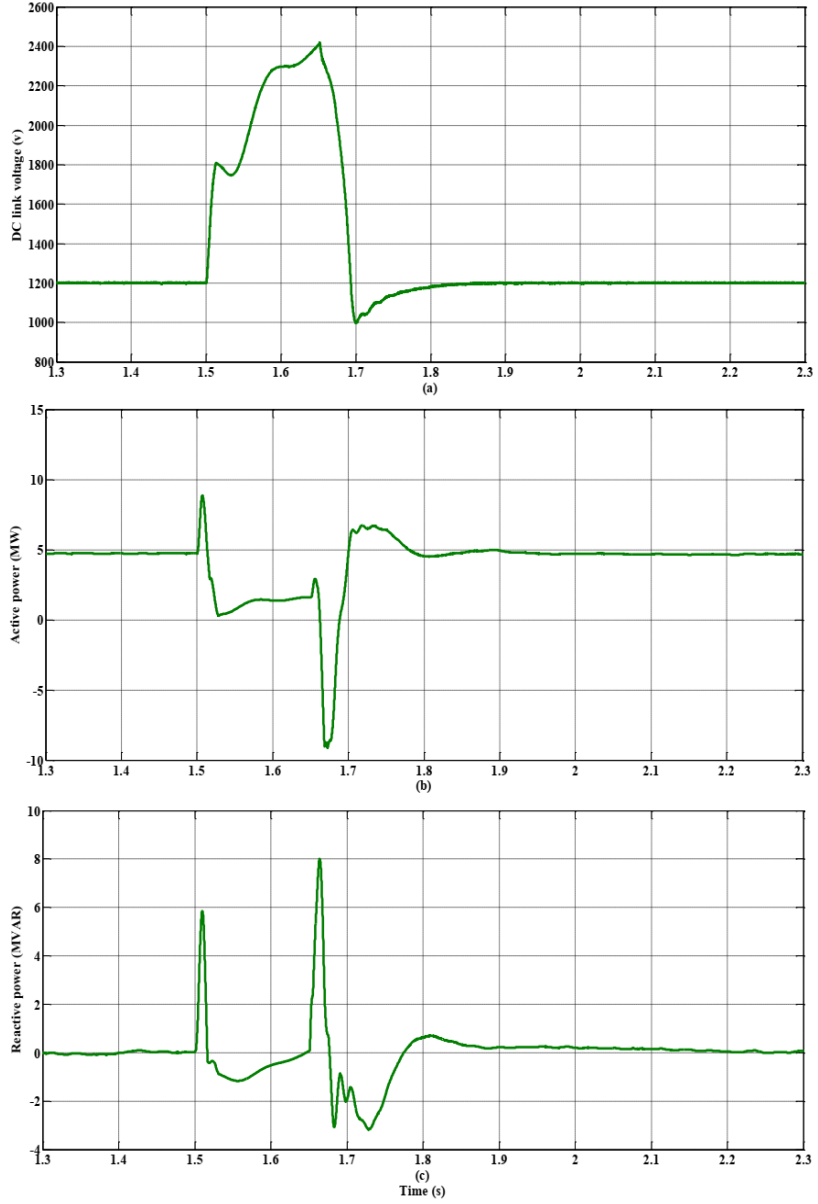

Fig. 11 Performance of studied system in case of stator series crowbar technique.

The fifth studied task studies the dynamic behavior of studied wind system with the outer terminal crowbar technique. The outer terminal crowbar technique works as the stator crowbar technique. The variations of DC-link voltage, active power, and reactive power are illustrated in Fig. 12.

The crowbar techniques successfully decreases the overshoots of DC link capacitor voltage during fault occurrence where it returns quickly to its rated value during post-fault duration. Finally, the simulation results show that, the various crowbar techniques improve the dynamic behaviour of studied WTs and, it leads to DFIG WTs can stay in service and become more stable during fault duration.
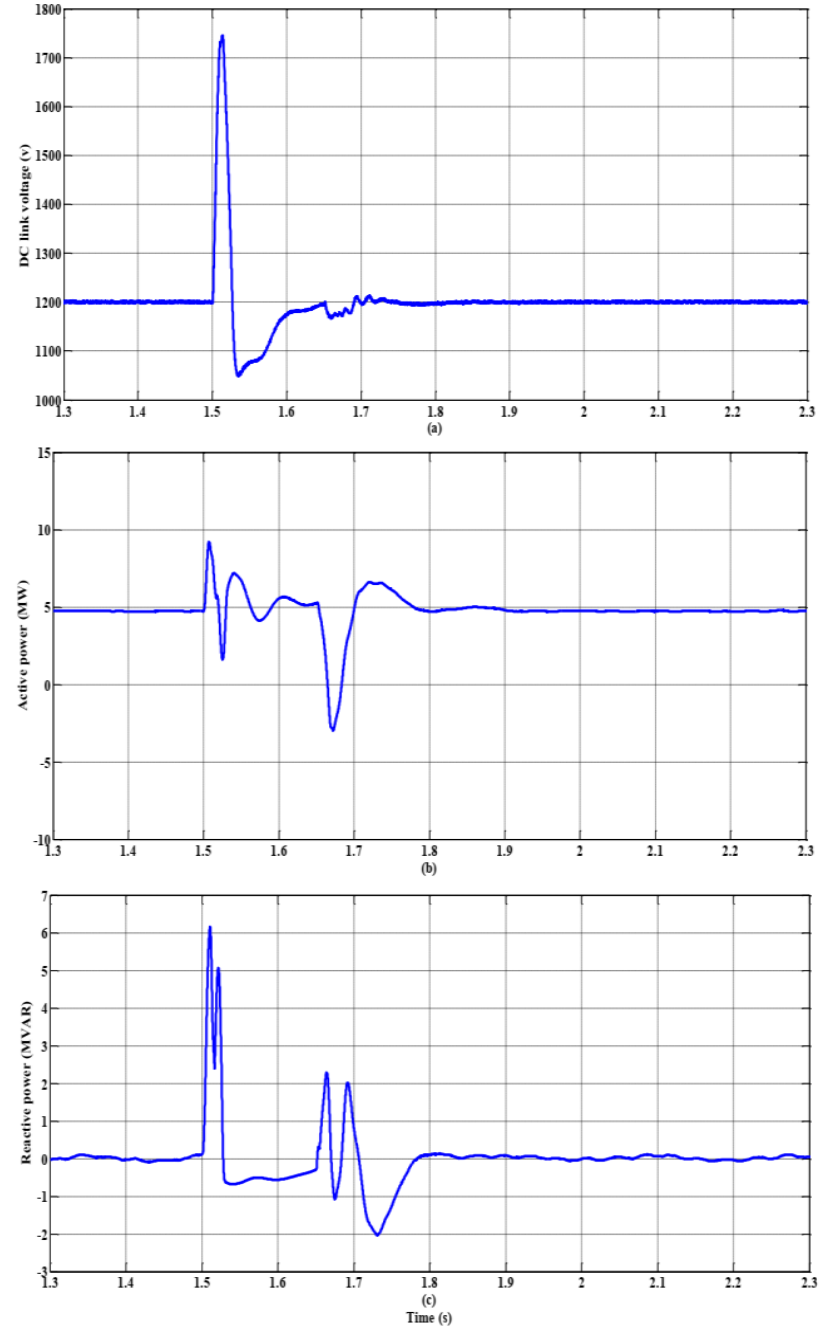

Fig. 12 Performance of studied system in case of outer terminal crowbar technique.

\subsection{Comparative study}

In this subsection, the comparative study of various tasks is investigated. The influence of the different crowbar types on the dynamic behavior of the studied system during fault is shown in Figs 13-15. 
As shown in Fig. 13, the value of DC link voltage varies according to the connected crowbar types to the studied wind farm. The DC link voltage value is high in case of without any crowbar technique and stator series crowbar technique compared with other techniques. The minimum value of the DC-link voltage is observed in other cases, but the outer terminal crowbar technique is preferred using because of the DC link voltage value decreases rapidly compared with other techniques.

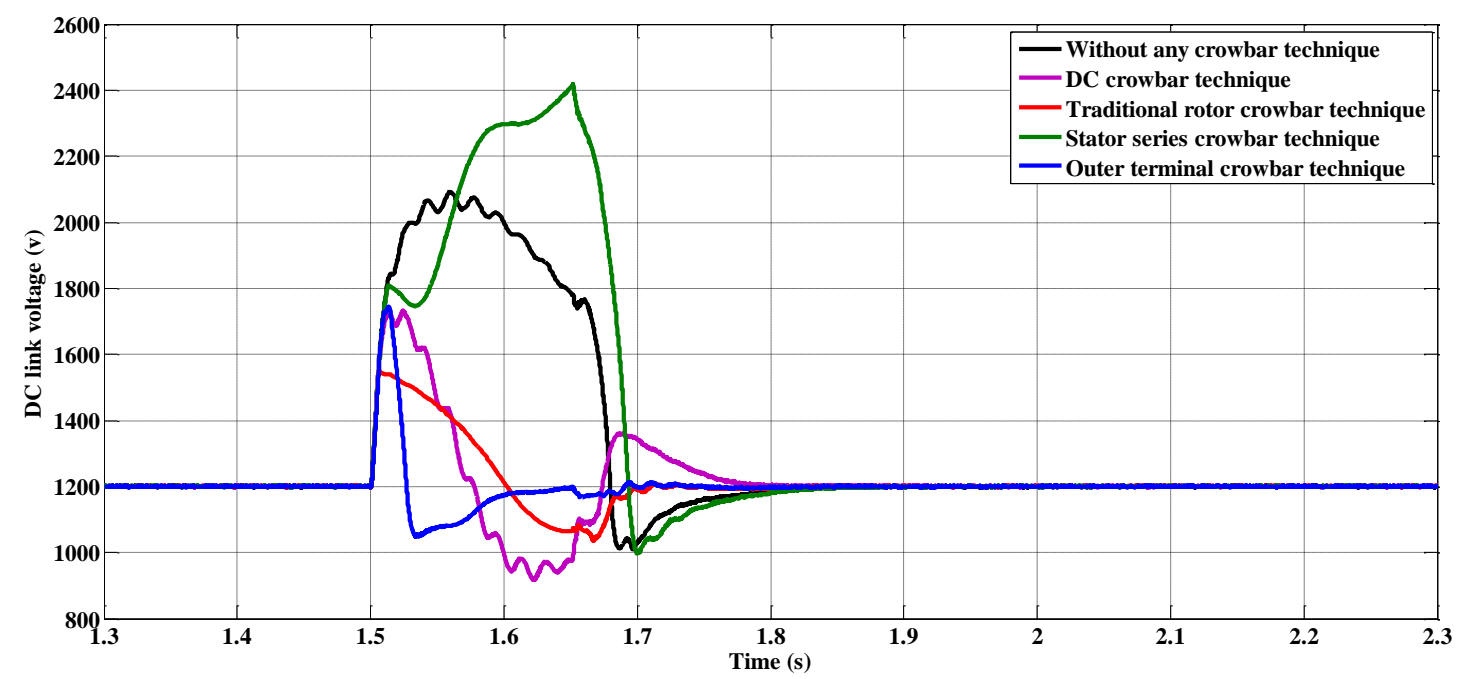

Fig. 13 Comparison of DC link voltage responses during different crowbar techniques.

As shown in Fig. 14, the value of active power varies according to the connected crowbar types to the studied wind farm. The active power captured from the studied system in case of using the outer terminal crowbar technique is more stable than the other cases, where in the other techniques are decreased nearly to zero value.

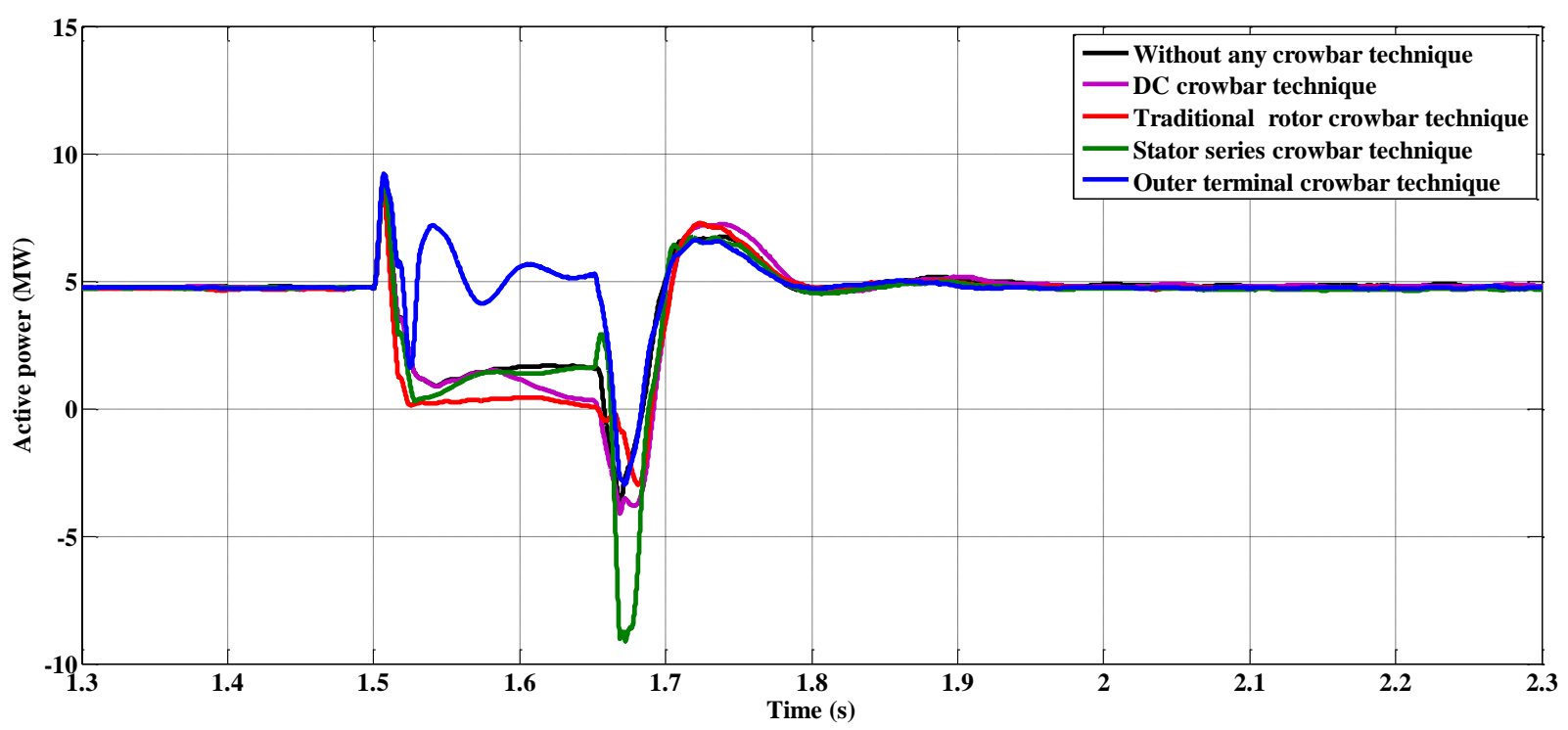

Fig. 14 Comparison of active power responses during different crowbar techniques.

As shown in Fig. 15, the value of reactive power varies according to the connected crowbar types to the studied wind farm. The fluctuation of reactive power from the studied system equipped with the outer terminal crowbar technique is more stable than the other cases. 


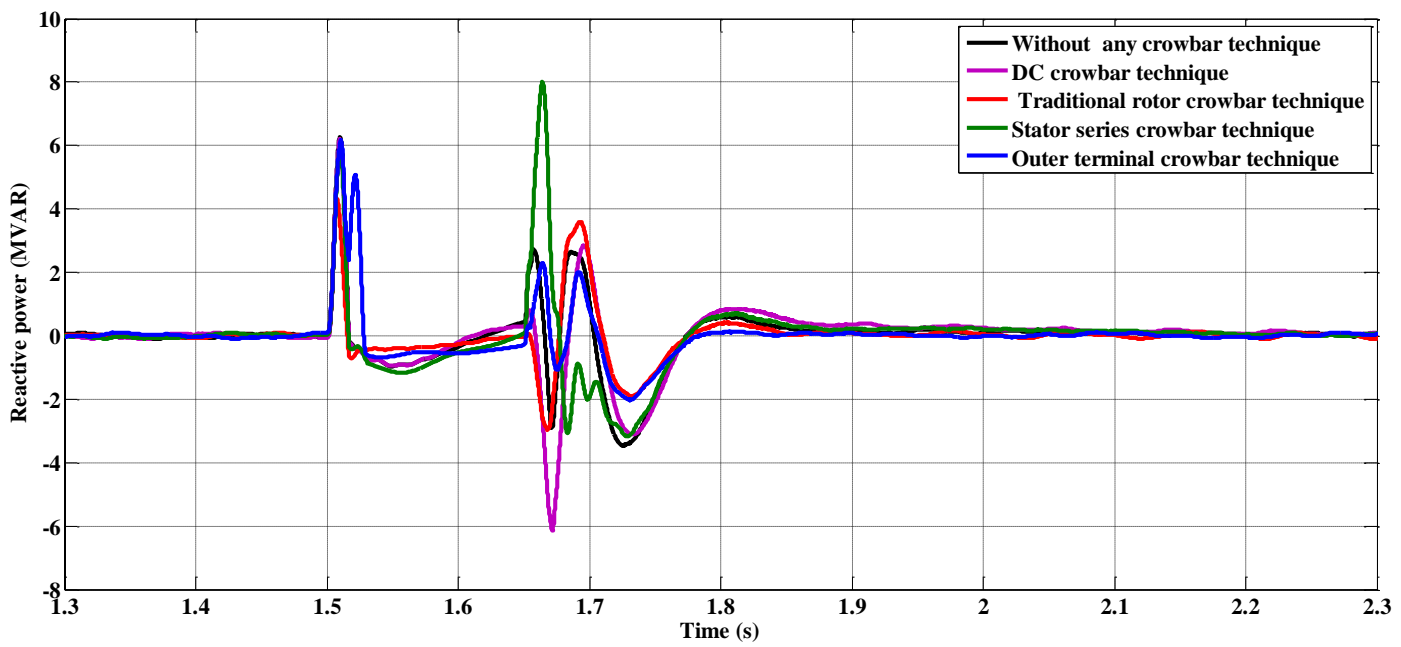

Fig. 15 Comparison of reactive power responses during different crowbar techniques.

Finally from all studied results, the values of DC link voltage, active power, and reactive power in case of outer terminal crowbar technique have low fluctuations during and post fault duration and also, the studied system returns to the steady state case in a period less than that of the other studied cases. The outer terminal crowbar technique is preferred using because of it provides the required protection for the WT components.

\section{Conclusion}

This paper has reviewed the various concepts of crowbar techniques about the WT control system. The crowbar techniques are important to prevent the disconnection of DFIG-WTs during fault conditions. The ANFIS control switching strategy of the different crowbar techniques are triggered when a short circuit occurred which leads to high increasing of the DC-link voltage. During the grid fault, in case of with crowbar technique, the DC link voltage of the converter of DFIG-WT is rapidly increasing and also, the active power is rapidly decreasing. So, the crowbar control method is presented to improve the fault ride-through capability of WT. The impacts of various crowbar techniques on the performance of studied system are investigated. The performances of DFIG based WTs with various crowbar techniques during faults are simulated. The results show that the crowbar techniques based on ANFIS has obvious effect for enhancing the stability of studied system. The results prove that, the fluctuations dynamic performance of system parameters has little fluctuations in case of outer terminal crowbar technique. The electrical power converters are still connected with using the outer terminal crowbar so the controllability of the DFIG will not be lost. Also, the system with the outer terminal crowbar technique can return to the steady state case in a time less than that of the other techniques.

\section{References}

[1] A. Dida, and D. Benattous, "A complete modeling and simulation of DFIG based wind turbine system using fuzzy logic control," Journal of Frontiers Energy, vol. 10, no. 2, pp. 143-154, 2016.

[2] X. Guo et al., "Analysis and Enhancement of Active Power Transfer Capability for DFIG-Based WTs in Very Weak Grid," in IEEE Journal of Emerging and Selected Topics in Power Electronics, 2021, doi: 10.1109/JESTPE.2021.3089235.

[3] T. M. S.M. Muyeen, R. Takahashi, T. Murata, J. Tamura, M.H. Ali, Y. Matsumura, and A. Kuwayama, "Low voltage ride through capability enhancement of wind turbine generator system during network disturbance," Renew. Power Gener. IET, vol. 3, no. 1, pp. 65-74, 2009.

[4] C. Rahmann et al., "Justified Fault-Ride-Through Requirements for Wind Turbines in Power Systems," IEEE Trans. POWER Syst., vol. 26, no. 3, pp. 1555-1563, 2011.

[5] Y. Ren and W. Zhang, "A Novel Control Strategy of an Active Crowbar for DFIG-Based Wind Turbine during Gird Faults Yuan Ren," IEEE Int. Electr. Mach. Drives Conf., pp. 1137-1142, 2011.

[6] Y. Ling, "The fault ride through technologies for doubly fed induction generator wind turbines," Wind Eng., vol. 40, no. 1, pp. 31-49, 2016.

[7] S. Yang, T. Zhou, D. Sun, Z. Xie, and X. Zhang, "A SCR crowbar commutated with power converter for DFIG-based wind turbines," Int. J. Electr. Power Energy Syst., vol. 81, pp. 87-103, 2016.

[8] G. Pannell, D. J. Atkinson, and B. Zahawi, "Minimum-Threshold Crowbar for a Fault-Ride-Through Grid-Code-Compliant DFIG Wind Turbine," IEEE Trans. ENERGY Convers., vol. 25, no. 3, pp. 750-759, 2010.

[9] O. Noureldeen, "Behavior of DFIG Wind Turbines with Crowbar 
Protection under Short Circuit," Int. J. Electr. Comput. Sci. IJECS-IJENS, vol. 12, no. 3, pp. 32-37, 2012.

[10] M. Ebeed, O. Noureldeen, and A. A. Ebrahim, "Assessing Behavoir of the Outer Crowbar Protection with the DFIG during Grid Fault," 2nd Int. Conf. Energy Syst. Technol. 18 21 Feb. 2013, Cairo, Egypt, pp. 1-12, 2013.

[11] O. Noureldeen, "A Novel Crowbar Protection Technique for DFIG Wind Farm during Fault Ride Through,” Int. J. Eng. Technol. IJET-IJENS, vol. 12, no. 3, pp. 85-95, 2012.

[12] S. Hu, X. Zou, and Y. Kang, "A novel optimal design of DFIG crowbar resistor during grid faults," 2014 Int. Power Electron. Conf. IPEC-Hiroshima - ECCE Asia 2014, pp. 555-559, 2014.

[13] A. P. G. and Maurício B. C. Salles, Kay Hameyer, José R. Cardoso and C. Rahmann, "Crowbar System in Doubly Fed Induction Wind Generators," energies, vol. 3, pp. 738-753, 2010.

[14] J. Zhu, Jiebei, et al. "A DC chopper-based fast active power output reduction scheme for DFIG wind turbine generator," IET Renewable Power Generation, 2021, doi: 10.1049/rpg2.12178

[15] F.Sulla, J.Svensson, , and O.Samuelsson, "Short-circuit analysis of a doubly fed induction generator wind turbine with direct current chopper protection," Journal of Wind Energy, vol. 16, pp. 37-49, 2013.

[16] G. Pannell, B. Zahawi, J. D. Atkinson, and P. Missailidis, “ Evaluation of the performance of a DC-link brake chopper as a DFIG low-voltage fault-ride-through device," Journal of IEEE Transactions on Energy Conversion, vol. 28, no. 3, pp. 535-542, 2013.

[17] O. Noureldeen, and I. Hamdan , "An Efficient ANFIS Crowbar Protection for DFIG Wind Turbines during Faults," In: Proceedings of IEEE Nineteenth International Middle East Power Systems Conference (MEPCON), Cairo, Egypt; December 19-21, 263-269, 2017.

[18] O. Noureldeen, and I. Hamdan , “ Design of robust intelligent protection technique for large-scale grid-connected wind farm," Journal of Protection and Control of Modern Power Systems, vol. 3, no. 17, pp. 1-13, 2018.

[19] O. Noureldeen, and I. Hamdan, “ A novel controllable crowbar based on fault type protection technique for DFIG wind energy conversion system using adaptive neuro-fuzzy inference system," Journal of Protection and Control of Modern Power Systems, vol. 3, no. 35, pp. 1-12, 2018.

[20] O. Noureldeen, and I. Hamdan , “ Design and Analysis of Combined Chopper-Crowbar Protection Scheme for Wind Power System Based on Artificial Intelligence," In: Proceedings of IEEE Twentieth International Middle East Power Systems Conference (MEPCON), Cairo, Egypt; December 18-20, 809-814, 2018.

[21] O. Noureldeen, I. Hamdan, and B. Hassanin, "Design of advanced artificial intelligence protection technique based on low voltage ride-through grid code for large-scale wind farm generators: a case study in Egypt," Journal of SN Applied Sciences, 2019, doi: 10.1007/s42452-019-0538-9.
[22] A. Ramadan, S. Kamel, A. Rashad and J. Yu, "Design of Fuzzy Logic Control for Direct and Quadratic Components of DFIG's Rotor and Grid Side Control System Based Wind Turbines," 2018 Twentieth International Middle East Power Systems Conference (MEPCON), 2018, pp. 655-659, doi: 10.1109/MEPCON.2018.8635267.

[23] I. Hamdan, A. Maghraby, and O. Noureldeen, "Stability improvement and control of grid-connected photovoltaic system during faults using supercapacitor," Journal of SN Applied Sciences, 2019, doi.org/10.1007/s42452-019-1743-2.

[24] H. Taheri, S. Sodoudi, A.Kerschbaumer, and U. Cubasch, "A new structure identification scheme for ANFIS and its application for the simulation of virtual air pollution monitoring stations in urban areas," Journal of Engineering Applications of Artificial Intelligence, vol. 41, pp. 175-182, 2015.

[25] D. Zheng, A. T. Eseye, J. Zhang, and H. Li, “ Short-term wind power forecasting using a double-stage hierarchical ANFIS approach for energy management in microgrids," Journal of Protection and Control of Modern Power Systems, vol. 2, no. 13, pp. 1-10, 2017.

[26] H. Nguyen, et al., "Evaluating and predicting blast-induced ground vibration in open-cast mine using ANN: a case study in Vietnam," Journal of SN Applied Sciences vol. 1, no. 125, 2018, https://doi.org/10.1007/s42452-018-0136-2

[27] K.V. Shihabudheen, S. K. Raju, and G.N. Pillai, "Control for grid-connected DFIG-based wind energy system using adaptive neuro-fuzzy technique," Journal of International Transactions on Electrical Energy Systems, vol. 28, no. 5, pp. 1-18, 2018. 